\title{
Tough problem, creative solution
}

\author{
Jacob A. Klapper, MD, and Matthew G. Hartwig, MD
}

\author{
From the Department of Cardiothoracic Surgery, Duke University Medical Center, Durham, NC. \\ Disclosures: Authors have nothing to disclose with regard to commercial support. \\ Received for publication Oct 27, 2016; accepted for publication Oct 27, 2016; available ahead of print Nov, 2016. \\ Address for reprints: Jacob A. Klapper, MD, Division of Cardiothoracic Surgery, DUMC 3954, Durham, NC \\ 27710 (E-mail: Jacob.klapper@duke.edu). \\ J Thorac Cardiovasc Surg 2017;153:476 \\ 0022-5223/\$0.00 \\ Published by Elsevier Inc. on behalf of The American Association for Thoracic Surgery \\ http://dx.doi.org/10.1016/j.jtcvs.2016.10.038
}

Nakajima and colleagues ${ }^{1}$ describe an unconventional, but successful, approach to cross-field ventilation. Because of the extent of the tumor in the left mainstem bronchus and the presence of indwelling stents, the authors felt compelled to find an alternative to cross-field ventilation via the left mainstem bronchus. The success of both their approach and the patient exemplify the importance of executing forethought in preparation for these difficult cases.

As Nakajima and colleagues ${ }^{1}$ mention, this operation could have been performed on extracorporeal membrane oxygenation (ECMO) or cardiopulmonary bypass, both of which they elected to avoid out of concern for bleeding. Although cardiopulmonary bypass certainly would have necessitated full heparinization, both venovenous and venoarterial ECMO are now being used routinely in lung transplantation, typically with low doses of heparin and activated clotting times from 180 to 200 seconds, thus lowering the risk of bleeding both intraoperatively and postoperatively. Another criticism of this report would be the authors' decision to use a clamshell thoracotomy, a more morbid procedure than a median sternotomy. With this in mind, I would argue that a far more simplistic approach to this operation would have been median sternotomy with venoarterial ECMO using low-dose heparinization. The overarching benefit being that Nakajima and colleagues ${ }^{1}$ could have avoided the need to correct ventilation perfusion mismatch by encircling the right pulmonary artery, and they would not have been required to derive an alternative method for cross-field ventilation. Plus, with venoarterial ECMO via the groin, they would have cleared the operative field of cumbersome sterile ventilation tubing or, as is the case with central venoarterial ECMO, venous and arterial cannulas.

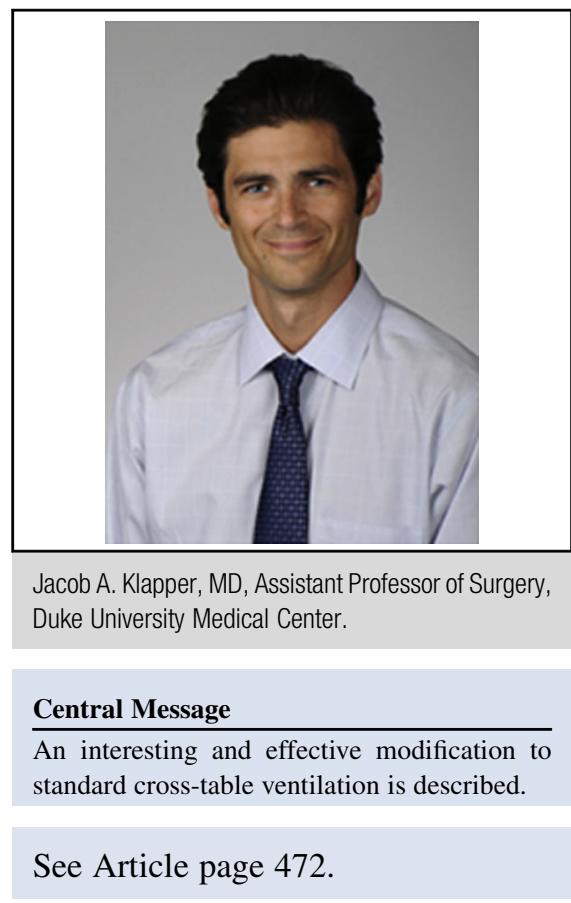

These criticisms aside, this description of how Nakajima and colleagues ${ }^{1}$ performed this operation remains valuable because not all facilities have ECMO capabilities and not all surgeons are comfortable using this technology. Thus, in difficult clinical situations, such as this one, other options must be considered. Thus, although it is unlikely that an approach, such as the one described, would ever be routinely used given the rarity of these airway tumors, this report demonstrates a creative take on cross-field ventilation and an acute understanding of how to overcome ventilation perfusion mismatch and avoid the need for cardiopulmonary bypass or ECMO.

\section{Reference}

1. Nakajima T, Yoshida S, Yoshino I. Left carinal pneumonectomy using left bronchostomy: a novel technique of crossfield intubation. J Thorac Cardiovasc Surg $2017 ; 153: 472-5$. 